\title{
CD4+ T cells memorize obesity and promote weight regain
}

\author{
Jianghuan Zou ${ }^{1}$, Beibei Lai ${ }^{1}$, Mingzhu Zheng ${ }^{2}$, Qin Chen ${ }^{1}$, Shujun Jiang ${ }^{1}$, Anying Song ${ }^{1}$, Zan Huang ${ }^{1}$, \\ Peiliang Shi ${ }^{1}$, Xin Tu${ }^{1}$, Di Wang ${ }^{2}$, Linrong $\mathrm{Lu}^{2}$, Zhaoyu Lin ${ }^{1}$ and Xiang Gao ${ }^{1}$
}

Body weight regain often causes failure of obesity therapies while the underlying mechanism remains largely unknown. In this study, we report that immune cells, especially CD4+ T cells, mediate the 'memory' of previous obese status. In a weight gain-loss-regain model, we found that C57BL/6J mice with an obesity history showed a much faster rate of body weight regain. This obesity memory could last for at least 2 months after previously obese mice were kept at the same body weight as non-obese mice. Surprisingly, such obesity memory was abrogated by dexamethasone treatment, whereas immunodeficient Rag1 $1^{-/-}$and $\mathrm{H}_{2} \mathrm{~A}^{-l-}$ mice failed to establish such memory. Rag1-I- mice repossessed the obesity memory when immune cells or CD4+ T cells isolated from previously obese mice were transferred. Furthermore, depletion of CD4+ T cells led to obesity memory ablation. Taken together, we conclude that CD4+ $\mathrm{T}$ cells mediate obesity memory and promote weight regain.

Cellular \& Molecular Immunology advance online publication, 19 June 2017; doi:10.1038/cmi.2017.36

Keywords: CD4+ T cell; immunodeficiency; metabolism; obesity memory; weight regain

\section{INTRODUCTION}

Obesity is a major public health problem that is causally associated with many diseases, including type II diabetes, hepatic steatosis, cardiovascular diseases and systemic chronic inflammation. ${ }^{1-4}$ Anti-obesity drugs, as well as lifestyle interventions, have been developed for the weight loss of obese patients. Unfortunately, although many of these treatments are effective at the beginning of intervention, it is difficult to maintain a $10 \%$ body weight reduction in the first year and most patients typically regain $30-50 \%$ of their initial weight during the next $2-3$ years. ${ }^{5-7}$ Some patients even obtain a heavier body weight with severe adiposity after treatment. ${ }^{8}$ Clinical studies have confirmed that weight regain emerges regardless of different therapy types, including lifestyle intervention, pharmacotherapy and bariatric surgeries. ${ }^{9-11}$ Moreover, body weight regain can occur not only after therapy termination but also during the treatment. ${ }^{12}$ It is often accompanied by a recurrence of obesity-related comorbidities. ${ }^{13}$ Overall, there seems to be a strong tendency for individuals who experienced obesity to regain lost weight and fat. ${ }^{14}$

The underlying mechanism for weight regain is largely unknown. A commonly assumed perspective is that weight regain is caused by metabolic adaptions, such as increased appetite and reduced energy expenditure. ${ }^{15}$ Previous studies have demonstrated that weight loss leads to a significant increase in orexigenic hormones, including ghrelin and glucagon-like peptide-1 (GLP-1), ${ }^{16-18}$ and a decrease in anorexigenic hormones, including peptide YY (PYY), cholecystokinin (CCK) and leptin. ${ }^{19}$ Weight loss also reduces total energy expenditure, thus favoring weight regain. ${ }^{20}$ However, weight regain was correlated with higher leptin and lower ghrelin levels in human patients. ${ }^{21}$ Appetite sensation and resting metabolic rate also remained unaffected after weight reduction. ${ }^{22}$

Chronic systemic inflammation is associated with obesity onset. Immune cells, especially $\mathrm{T}$ lymphocytes, have a crucial role in obesity-related inflammation. ${ }^{23}$ Activated CD4+ T cells were shown to accumulate in adipose tissue before

\footnotetext{
${ }^{1}$ State Key Laboratory of Pharmaceutical Biotechnology and MOE Key Laboratory of Model Animal for Disease Study, Model Animal Research Center, Nanjing Biomedical Research Institute, Nanjing University, 12 Xuefu Road, Pukou District, Nanjing, Jiangsu 210061, China and ${ }^{2}$ Institute of Immunology, Program in Molecular and Cellular Biology, Zhejiang University School of Medicine, Hangzhou, Zhejiang 310058, China Correspondence: X Gao, Ph.D, and Z Lin, Ph.D, State Key Laboratory of Pharmaceutical Biotechnology and MOE Key Laboratory of Model Animal for Disease Study, Model Animal Research Center, Nanjing Biomedical Research Institute, Nanjing University, 12 Xuefu Road, Pukou District, Nanjing, Jiangsu 210061, China.
}

E-mail: gaoxiang@nju.edu.cn or linzy@nju.edu.cn

Received: 15 March 2017; Revised: 20 April 2017; Accepted: 20 April 2017 
inflammatory macrophage infiltration, which contributed to inflammatory cell activation. ${ }^{24}$ Recent studies have also indicated that the IL-33/ST2 axis was crucial for the proliferation and differentiation of visceral adipose tissue-resident regulatory $\mathrm{T}$ cells (Tregs, a subset of CD4+ T cells), whereas the increased Tregs could restrain the obesity-induced inflammation in adipose tissue and thereby improve obesity-associated metabolic parameters. ${ }^{25,26}$

Intriguingly, accumulating evidence has also highlighted the potential roles of chronic systemic inflammation in weight regain. Increases in leukocytes and neutrophils in circulation and HAM56 (human alveolar macrophage) in adipose tissue were utilized to predict unsuccessful weight reduction and rapid weight regain. ${ }^{27}$ Weight cycling induced T lymphocyte accumulation in epididymal adipose tissue. ${ }^{28} \mathrm{CD} 4+$ effector $\mathrm{T}$ cell-mediated macrophages were shown to be recruited and retained in the adipose tissues of previously obese mice, despite normalized body weight. ${ }^{29,30}$ Meanwhile, when subjected to short-term fasting followed by refeeding or long-term weight loss intervention, inflammatory mediators including tumor necrosis factor alpha (TNF- $\alpha$ ) and interleukin 6 (IL-6) were elevated in epididymal adipose tissue. ${ }^{15,31}$ These results suggest a potential link between chronic systemic inflammation and weight regain. However, the underlying mechanism and biological significance remain unclear.

In this study, we provide evidence that mice with obesity experience displayed much faster body weight regain, which was not due to physiological adaptions. This obesity memory had a long-lasting effect, and it was mainly mediated by CD4+ $\mathrm{T}$ cells from previously obese mice.

\section{MATERIALS AND METHODS}

\section{Animals and diets}

Mice were provided by the Model Animal Research Center (MARC) of Nanjing University (Nanjing, Jiangsu Province, China) and housed in a specific pathogen-free (SPF) and Association for Assessment and Accreditation of Laboratory Animal Care International (AAALACI) accredited animal facility. All experiments were performed according to the animal protocol approved by the MARC Animal Care and Use Committee. For most studies, 8-week-old mice were separated into two groups, an obesity history group $(\mathrm{MOH})$ and a control group (CTR). The $\mathrm{MOH}$ group was fed a high fat diet (HFD, 60\% energy from fat, Research Diets, New Brunswick, NJ, USA) for 1 month (weight gain period). Then, the $\mathrm{MOH}$ mice underwent calorie restriction to lose weight. It took about 3 weeks for the $\mathrm{MOH}$ mice to reach the same body weight as the even-aged CTR group (weight loss period). During the weight gain and loss period, the CTR group was fed a regular chow diet $(\mathrm{RD}, 6 \%$ energy from fat, Xietong Company, Nanjing, China). For weight maintenance, the $\mathrm{MOH}$ mice were kept at the same body weight as the CTR cohort after weight loss. Afterwards, both the $\mathrm{MOH}$ and the CTR groups were fed a HFD or RD ad libitum to induce weight regain.
Body weight and body composition measurement Body weight was measured once or twice per week at 1600 hours. The body weight increment ratio was calculated by dividing the weight gain during a certain period (weight regain or HFD feeding periods) by the body weight at the beginning of this period. For body composition measurements, mice were anesthetized with $2.5 \%$ avertin $(0.5 \mathrm{mg} / 10 \mathrm{~g}$ body weight) after overnight fasting (16 h). Lean mass, fat mass and bone mineral density (BMD) values were assessed with a dualenergy X-ray absorptiometry (DEXA) system (PIXImus 2, GE lunar, Chicago, IL, USA). Meanwhile, mouth to anus length was measured. For tissue weight measurements, mice were killed and tissues were isolated and weighed immediately.

\section{Blood glucose, GTT and ITT}

Blood was collected from mouse tail tips. The fasting (overnight) blood glucose and postprandial blood glucose levels were tested using a glucocard blood glucose test meter (GT-1640, ARKRAY, Kyoto, Japan). Glucose tolerance tests (GTT) and insulin tolerance tests (ITT) were carried out after fasting for 8- and 6-hour periods, from 0800 to 1600 hours or 1400 hours, respectively. Mice were intraperitoneally injected with $2 \mathrm{~g} / \mathrm{kg}$ body weight of D-(+)-glucose (G6152, Sigma, Virginia Beach, VA, USA) for the GTT and with $0.5 \mathrm{IU} / \mathrm{kg}$ body weight of insulin (Novo Nordisk, Tianjing, China) for the ITT. Blood glucose levels were detected at $0,15,30,45,60,90$ and $120 \mathrm{~min}$ after glucose/insulin injection.

\section{Blood cell counting and blood biochemistry}

Anticoagulant-treated whole blood was collected from the posterior orbital venous plexus of the mice with a $15 \mathrm{~g} / \mathrm{l}$ EDTA.2 K solution. Blood cell counting was performed immediately using a Hemavet 950FS Hematology Analyzer (Drew Scientific, Miami Lakes, FL, USA). For blood biochemical analysis, blood was collected from the venous sinus of the optical orbit and clotted by standing on ice for $2 \mathrm{~h}$. Sera were isolated by centrifugation at $3000 \mathrm{~g}$ at $4{ }^{\circ} \mathrm{C}$ for $20 \mathrm{~min}$ and stored at -20 and $-80^{\circ} \mathrm{C}$ for short- and long-term storage, respectively. Cholesterol (CHOL), triglyceride (TG), highdensity lipoprotein-cholesterol (HDL-C) and low-density lipoprotein-cholesterol (LDL-C) in the sera were detected with a 7600 Clinical Analyzer (Hitachi High-Technologies, Tokyo, Japan).

\section{Comprehensive Lab Animal Monitoring System}

Metabolic parameters of the mice were acquired with a computer-controlled open-circuit monitoring system (Oxymax indirect calorimetry system, Oxymax/CLAMS, Columbus Instruments, Columbus, OH, USA). The mice were housed individually in metabolic chambers with free access to water and a group-associated diet for at least 1 day of acclimation and 3 days of monitoring. Parameters including $\mathrm{O}_{2}$ consumption, $\mathrm{CO}_{2}$ production and daily food intake were detected and locomotor activities were measured on the $\mathrm{X}$ axis through infrared beams. Respiratory exchange ratio (RER) and heat 
production levels were calculated from the $\mathrm{O}_{2}$ consumption, $\mathrm{CO}_{2}$ production and daily food intake values.

Gene expression analysis

Total RNA was extracted from inguinal and epididymal adipose tissue and used for quantitative real-time PCR (qPCR) and microarray assays (Agilent Technologies, Capitalbio, Beijing, China). Data were analyzed using the chipster platform and normalized with the quantile normalization method. The accession number for the microarray data reported is GEO: GSE76944. The primers used for $\mathrm{qPCR}$ are listed in Supplementary Table S1.
Immunosuppressant treatment

Before weight loss, obese mice were intraperitoneally injected with $5 \mathrm{mg}$ dexamethasone sodium phosphate/kg body weight (Longship, Pizhou, China) per day for three consecutive days. Saline was injected into CTR mice as a control.

\section{Flow cytometry}

Epididymal adipose tissue was isolated and digested in collagenase II $(2 \mathrm{mg} / \mathrm{ml}$, Worthington Biochemical, Lakewood, NJ, USA) for $30 \mathrm{~min}$ in a $37^{\circ} \mathrm{C}$ water bath. After the adipose fraction and erythrocytes were removed, the cells were incubated with antibodies $\left(0.2 \mathrm{mg} / \mathrm{ml}\right.$ for each) at $4{ }^{\circ} \mathrm{C}$ for $30 \mathrm{~min}$. CD4-Cy5.5, CD8a-APC, TCR $\beta$-PE, TCR $\beta$-APC, IFN $\gamma$-FITC a
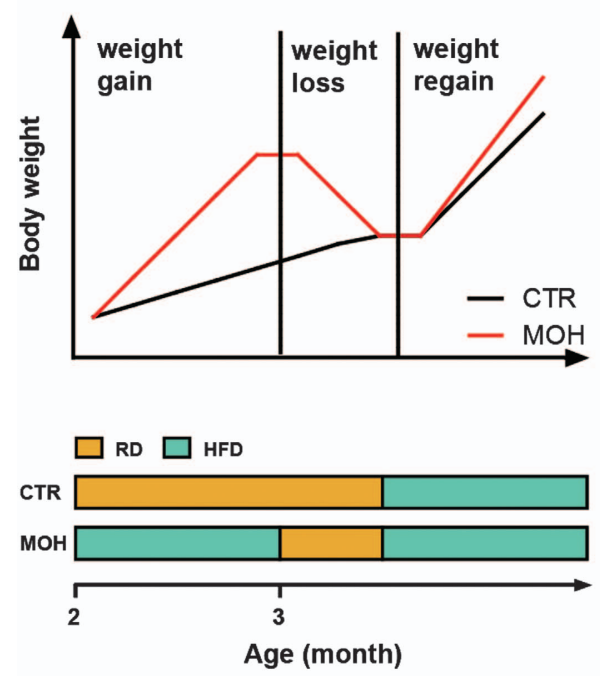

b

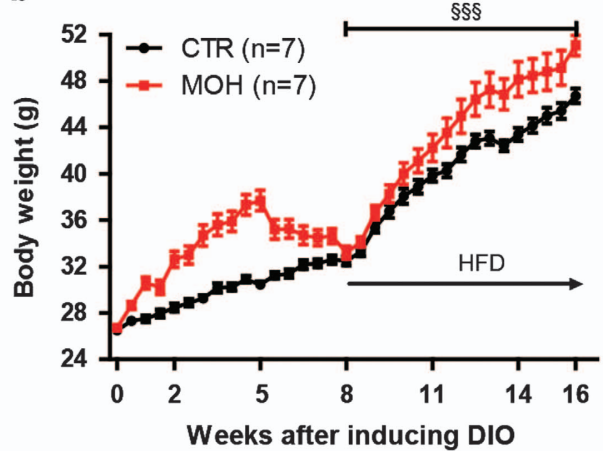

C

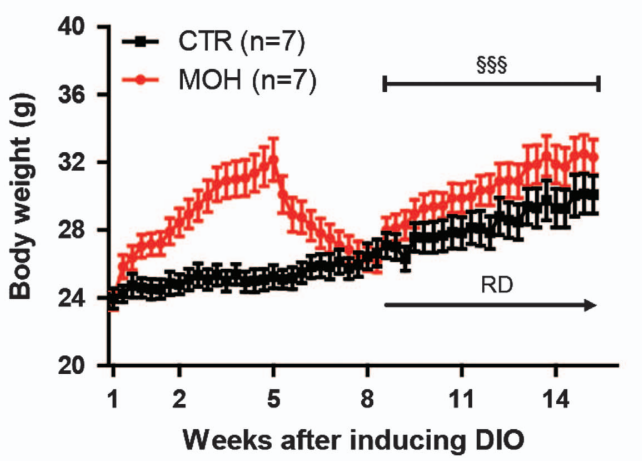

d

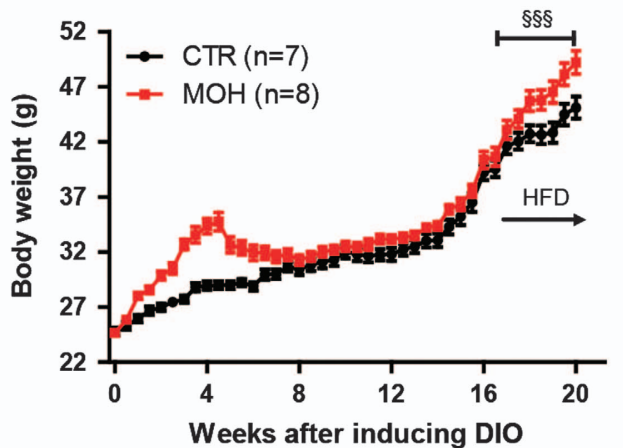

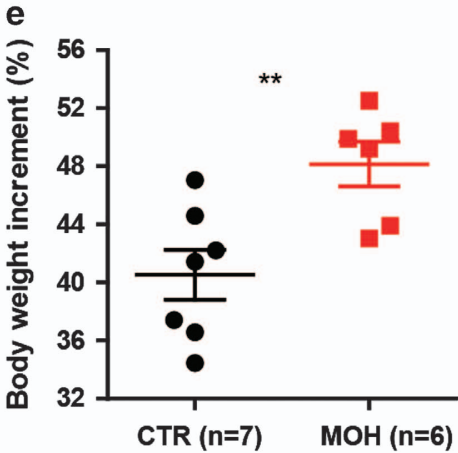

f
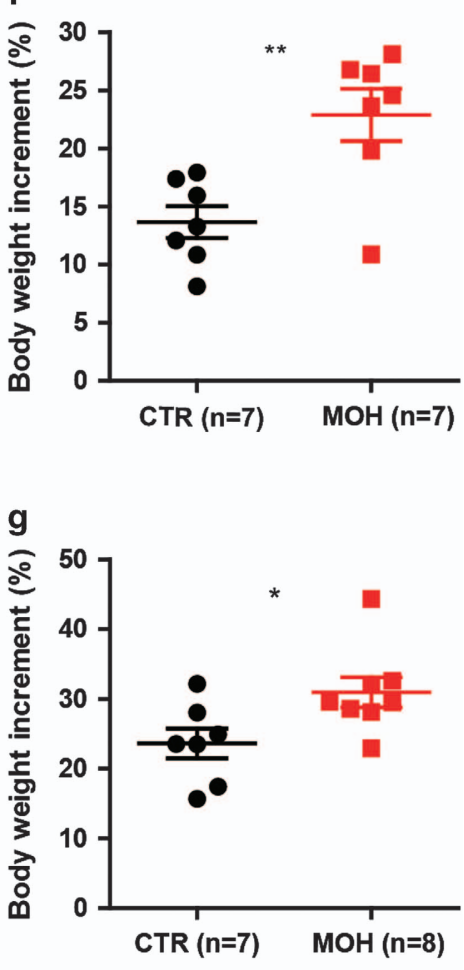

Figure 1 Weight gain-loss-regain model and long-term obesity memory. The DIO model in C57BL/6J mice was established as per the simulative graph and timeline (a). Body weight curves (b-d) and body weight increment ratios during the weight regain period (e-g) were recorded to display obesity memory. Weight regain was induced with a HFD (b, e and $\mathbf{d}, \mathbf{g}$ ) and a RD (d, f). The data are shown as means \pm s.d. ${ }^{*} P<0.05$ and ${ }^{*} P<0.01$, unpaired Student's $t$-test. ${ }^{\S \S} P<0.001$, two-way ANOVA followed by the Bonferroni post hoc test. CTR, control group; DIO, diet-induced-obesity; HFD, high fat diet; $\mathrm{MOH}$, obesity history group; RD, regular diet. 
and IL-17a-PE antibodies (Biolegend, San Diego, CA, USA) and CD4-FITC and CD8a-PE (Ebiosciences, San Diego, CA, USA) were used. To detect the T helper 1 (Th1) and T helper 17 (Th17) cells, associated cells were pre-stimulated with Phorbol-12-myristate-13-acetate (PMA) and ionomycine at $37^{\circ} \mathrm{C}$ for $30 \mathrm{~min}$ and then incubated with the corresponding antibodies. To detect the $\mathrm{CD} 4+\mathrm{T}$ cell depletion efficiency, erythrocyte-removed blood cells were incubated with CD4FITC and CD8a-PE antibodies. The stained cells were analyzed by flow cytometry (FACS Calibur, Becton Dickinson, Franklin Lakes, NJ, USA), and the data were analyzed with FlowJo software (Tree Star, Ashland, OR, USA).

\section{CD4+ T cell depletion}

After weight loss, mice were tail vein injected with $100 \mu \mathrm{g}$ antiCD4 antibody (GK 1.5, Ebioscience) once (dMOH, CD4+ T

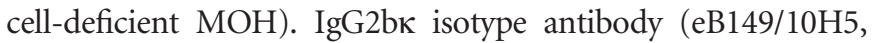
Ebioscience) was used as a negative control $(\mathrm{sMOH}, \mathrm{CD} 4+\mathrm{T}$ cell-sufficient MOH). CTR mice were injected with saline. Two weeks after injection, the mice were fed HFD. The depletion efficiency was measured by flow cytometry.

\section{Adoptive transfer}

EGFP transgenic mice (EGFP, C57BL/6J background) were used as donors to examine the transfer efficiency, as their splenocytes are EGFP-positive. The splenocytes of C57BL/6J mice were harvested before weight regain or after weight maintenance. A total of $2 \times 10^{7}$ cells were transferred into each recipient recombination-activating gene 1 knockout mouse $\left(\operatorname{Rag} 1^{-/-}\right)$via the tail vein. After 2 weeks, the recipient mice were fed HFD to induce weight regain.

\section{Statistics}

Data were statistically analyzed using unpaired two-tailed Student's $t$-tests or two-way ANOVA followed by the Bonferroni post hoc test. All data are expressed as the mean \pm s.d. A $P$-value $<0.05$ was considered statistically significant.

\section{RESULTS}

\section{Mice with an obesity history display faster weight regain after weight loss}

We designed a weight gain-loss-regain model with C57BL/6J mice (Figure 1a). Mice with an obesity history $(\mathrm{MOH})$ were fed a HFD for 1 month and then subjected to weight loss for about 3 weeks, whereas control mice (CTR) were fed a RD at the same time. Then, both groups were fed with the HFD to induce diet-induced-obesity (DIO). During this regain period, the $\mathrm{MOH}$ mice gained significantly more weight than the CTR cohort (Figures $1 \mathrm{~b}$ and $\mathrm{e}$ ), indicating a rapid obesity relapse. No difference was detected between the two cohorts in body length, BMD, skeletal content and lean mass (Supplementary Figures $1 \mathrm{a}-\mathrm{c}$ ). The extra weight gain in the $\mathrm{MOH}$ mice was attributed to greater fat accumulation (Supplementary Figures $1 \mathrm{c}$ and $\mathrm{d}$ ). The $\mathrm{MOH}$ mice consumed more oxygen during the daytime and generated a normal amount of carbon dioxide (Supplementary Figures 1e and f). The RER shift from 0.8 to
0.7 suggested that $\mathrm{MOH}$ mice were more inclined to acquire energy from fat oxidation after weight regain (Supplementary Figure 1g). $\mathrm{MOH}$ mice yielded more heat than CTR mice, whereas both cohorts displayed similar levels of physical activity and food intake (Supplementary Figures $1 \mathrm{~h}-\mathrm{j}$ ). In addition, $\mathrm{MOH}$ mice showed increased fasting and postprandial blood glucose levels and decreased insulin sensitivity (Supplementary Figures 1k and 1). Notably, $\mathrm{MOH}$ mice still displayed a higher weight gain rate even when the HFD was replaced with the $\mathrm{RD}$ during the weight regain period (Figures $1 \mathrm{c}$ and $\mathrm{f}$ ). These results suggest that after experiencing obesity, the mice retained a strong obesogenic tendency, which was independent of food type.

To determine how long this obesogenic tendency persists, $\mathrm{MOH}$ mice were given a mild food restriction to maintain body weight at a similar level to that of the RD-fed CTR mice for 2 months. Then, both cohorts were subjected to HFD feeding. We observed a similar phenomenon as before, with a faster weight regain in the $\mathrm{MOH}$ mice (Figures $1 \mathrm{~d}$ and g). This result indicated that the obesogenic tendency in previously obese mice was a long-lasting 'obesity memory'.

\section{Obesity memory is independent of hyperphagia, reduced thermogenesis or decreased metabolic rate}

Previous studies have suggested that increased appetite, reduced thermogenesis and decreased metabolic rate accompanying DIO contributed to weight regain. ${ }^{32}$ To examine whether metabolic abnormalities occurred in previously obese mice, we measured their body composition and metabolic parameters. In contrast to previous reports, we found that $\mathrm{MOH}$ mice after weight loss had not only the same body weight but also similar body length, BMD, skeletal content, lean mass and fat mass values as those in the CTR cohort (Figures 2a-e). Identical fasting and postprandial blood glucose levels and insulin sensitivity were also observed between the $\mathrm{MOH}$ and the CTR mice (Figures $2 \mathrm{f}$ and $\mathrm{g}$ ). $\mathrm{O}_{2}$ consumption, $\mathrm{CO}_{2}$ production and RER remained normal in $\mathrm{MOH}$ mice (Figures $2 \mathrm{~h}-\mathrm{j}$ ). Furthermore, physical activity, heat production and food intake were equivalent between the two cohorts (Figures $2 \mathrm{k}-\mathrm{m}$ ). These results suggest that the $\mathrm{MOH}$ mice following weight loss displayed unaffected glucose metabolism and energy homeostasis.

\section{Immune cells are essential for obesity memory}

We noticed that the spleens and thymuses were swollen in the $\mathrm{MOH}$ mice compared with the CTR mice after weight regain, suggesting that the immune system might be involved in this obesity memory (Supplementary Figure $1 \mathrm{~m}$ ). To further confirm this observation, we performed a microarray assay using inguinal adipose tissue from mice experiencing weight regain and confirmed the results via qPCR. Interestingly, immune-related signaling pathways, including $\mathrm{T}$ cell receptor (TCR), toll-like receptor (TLR) and Jak-STAT pathways, were significantly upregulated in $\mathrm{MOH}$ mice (Supplementary Figures 2a-e), suggesting an activation status. We further detected these alterations in both gonadal and inguinal adipose 
a

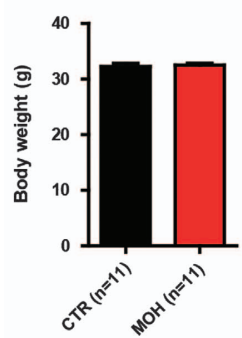

b

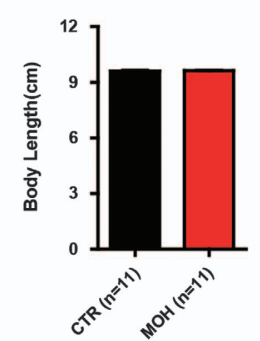

C

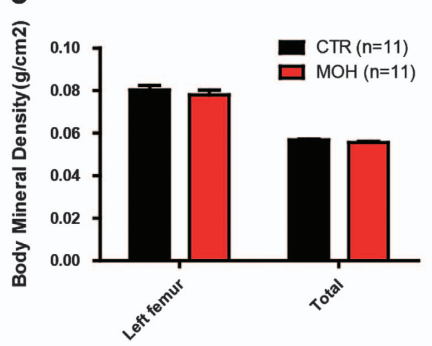

d

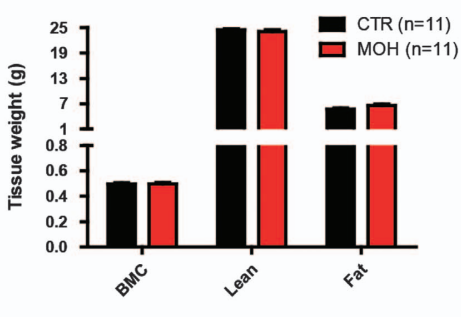

e

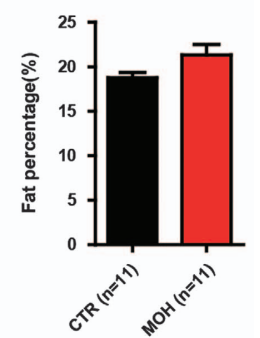

f

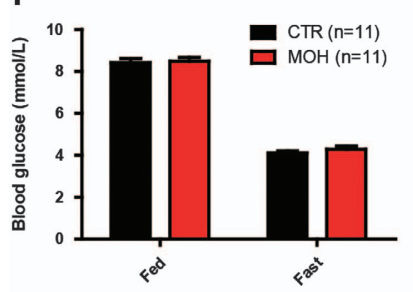

j

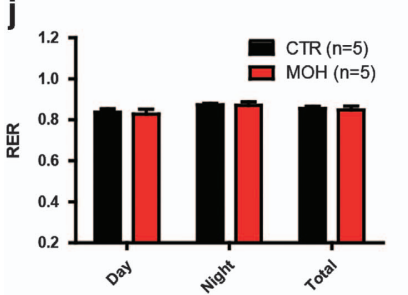

g
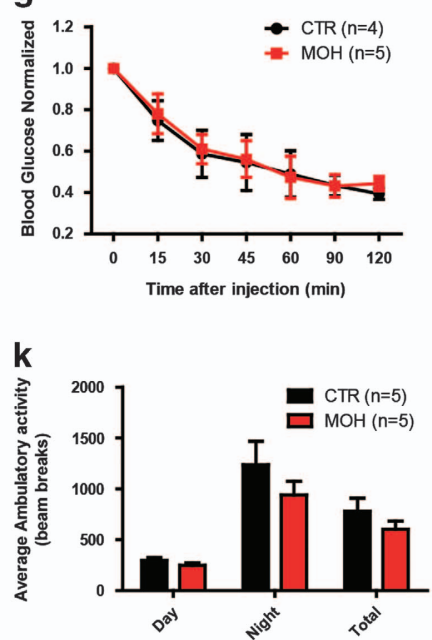

h

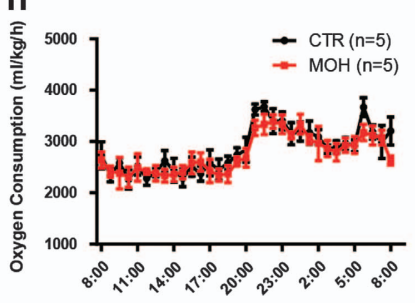

i
I

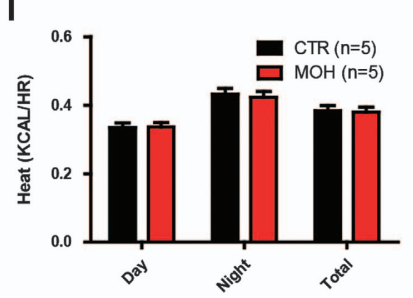

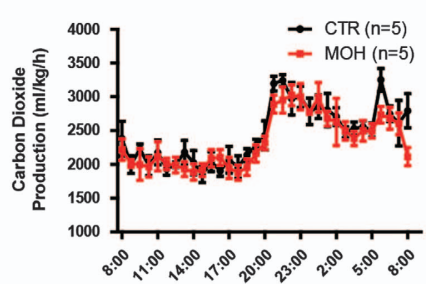

m

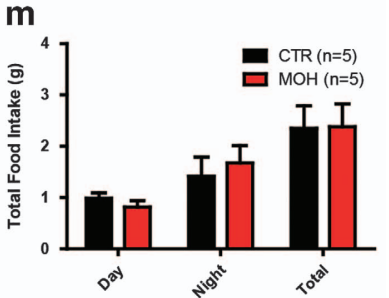

Figure 2 Metabolic parameters of C57BL/6J mice before weight regain. Body weight (a), body length (b), overall and local bone mineral density (c), bone mineral content, lean mass and fat mass (d) and body fat percentage (e) values were measured to determine body compositions, especially fat content, of the $\mathrm{MOH}$ and CTR mice. The fasting and postprandial blood glucose levels (f) and insulin sensitivity (g) were detected to determine glucose metabolism in both cohorts. $\mathrm{O}_{2}$ consumption (h), $\mathrm{CO}_{2}$ production (i), RER (j), ambulatory activity (k), heat production (I) and food intake $(\mathbf{m})$ were detected to examine energy expenditure. Data are shown as means \pm s.d. No difference was detected in this figure. CTR, control group; $\mathrm{MOH}$, obesity history group; RER, respiratory exchange ratio.

tissues from mice experiencing weight loss and found increased pro-inflammatory gene expression, including interferon $\gamma$ (IFN $\gamma$ ) (Supplementary Figures $2 \mathrm{f}$ and $\mathrm{g}$ ). Moreover, $\mathrm{T}$ cells, including CD4+, CD8+ T cells and Tregs, were significantly increased in adipose tissue, whereas their numbers remained unchanged in the spleens of $\mathrm{MOH}$ mice after weight regain (Supplementary Figures 3a and b). Before weight regain, the $\mathrm{T}$ cell numbers in the adipose tissue and spleens of $\mathrm{MOH}$ mice were higher than those in the CTR mice even though their body weights were identical (Supplementary Figures $3 c$ and d). Circulating white blood cells, including lymphocytes, monocytes and granulocytes (for example, eosinophils, neutrophils and basophils), were also increased before weight regain, suggesting a systemic immune activation status in these mice (Supplementary Figures 3e-i).

To further study the relationship between immune activation and obesity memory, we established a weight gain-lossregain model using Rag1 ${ }^{-/-}$mice, which lack mature $\mathrm{T}$ and $\mathrm{B}$ cells. ${ }^{33}$ Intriguingly, the $\mathrm{MOH}$ Rag1 ${ }^{-/-}$mice displayed no previous obesity memory as they showed similar weight gain rates during the weight regain period to those of the CTR Rag1 $1^{-/-}$mice (Figures $3 \mathrm{a}$ and b). Consistently, the $\mathrm{MOH}$ $\operatorname{Rag}^{-/-}$mice exhibited a similar body composition, as well as blood glucose and insulin sensitivities to those of the CTR Rag1 ${ }^{-/-}$mice after both weight regain and weight loss (Supplementary Figures $4 \mathrm{a}-\mathrm{f}$ and $5 \mathrm{a}-\mathrm{f}$ ). $\mathrm{MOH}$ Rag1-/- mice also showed similar energy metabolism as the CTR cohort after weight loss (Supplementary Figures $5 \mathrm{~g}-\mathrm{m}$ ). In addition, we suppressed systemic immunologic functions in C57BL/6J mice by injecting dexamethasone (dexa), a common immunosuppressant that inhibits $\mathrm{T}$ cells and pro-inflammatory cytokines, ${ }^{34}$ into mice after weight gain. Interestingly, these immunosuppressed $\mathrm{MOH}$ mice were unable to establish obesity memory (Figures $3 \mathrm{c}$ and $\mathrm{d}$ ). These results demonstrate that immune activation serves as a precondition for acquiring or implementing obesity memory.

To test whether immune cells from $\mathrm{MOH}$ are sufficient to transfer the stored 'obesity memory' to naive mice, we collected splenocytes from $\mathrm{MOH}$ and CTR mice after weight loss (Figure 3e) and transferred them into Rag1 $1^{-/-}$mice. We found that $\mathrm{MOH} \mathrm{Rag1}^{-/-}$recipients that received $\mathrm{MOH}$ mouse immune cells displayed significantly faster weight gain after being fed HFD (Figures $3 \mathrm{f}$ and $\mathrm{g}$ ). Considering that obesity memory is a long-lasting effect, we collected splenocytes after 1 month of body weight maintenance (Figure $3 \mathrm{~h}$ ) and performed the same adoptive transfer. The transfer of the 
a

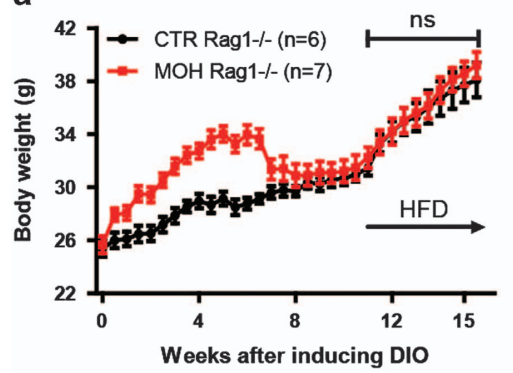

e

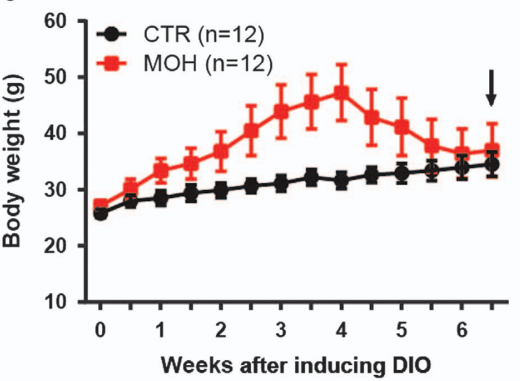

h

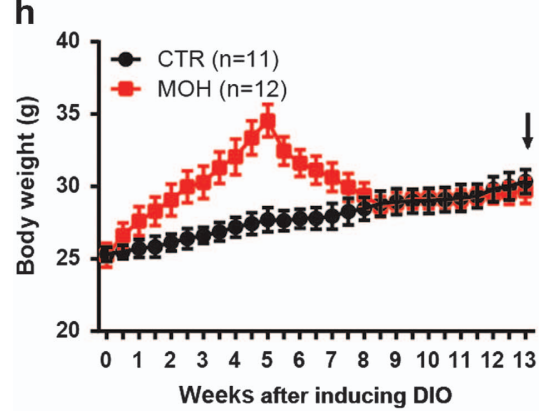

b

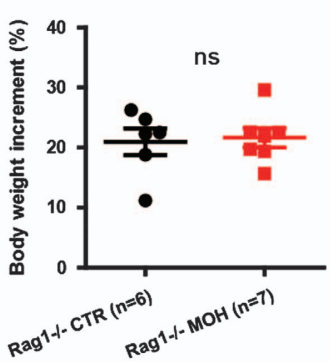

C

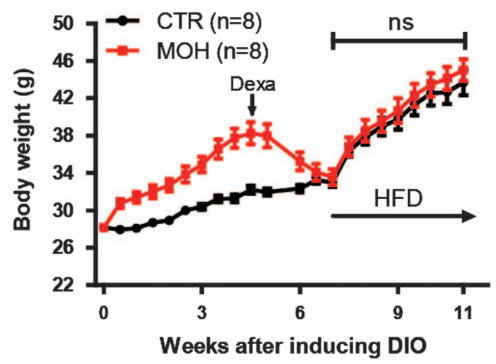

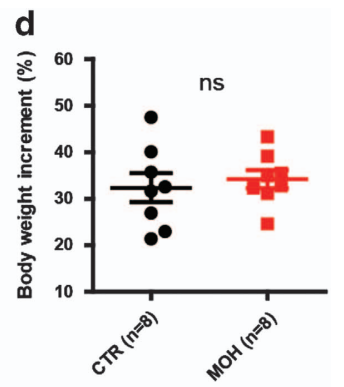

f

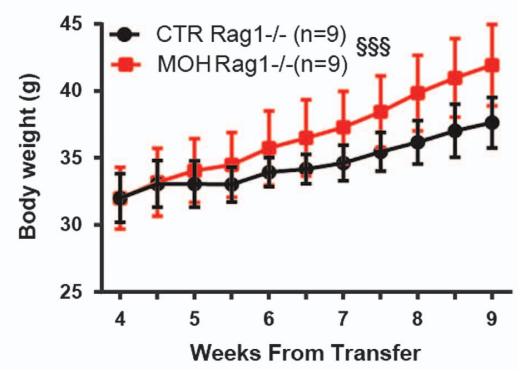

i

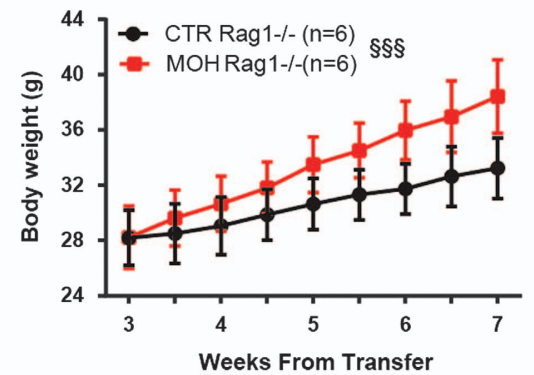

$g$

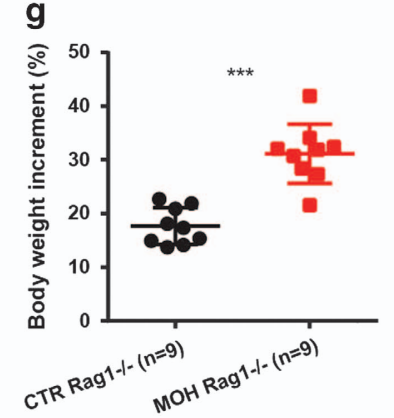

j

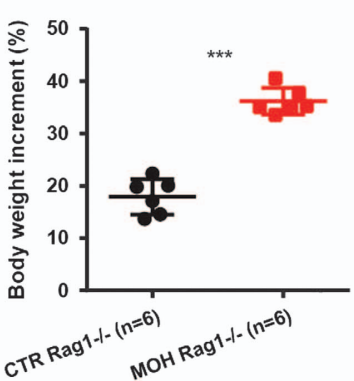

Figure 3 Immunodeficiency leads to failure in establishing obesity memory. Immunodeficient Rag $1^{-/-}$mice and C57BL/6J mice that were treated with dexamethasone (dexa) were subjected to a weight gain-loss-regain cycle. Body weight curve (a, c) and body weight increment ratio values during the weight regain period $(\mathbf{b}, \mathbf{d})$ were recorded to examine obesity memory in Rag $1^{-/-}$mice $(\mathbf{a}, \mathbf{b})$ and dexa-treated C57BL/6J mice (c, d), respectively. Adoptive transfer of splenocytes was performed to determine the role of immune cells in memorizing obesity. The body weight curves of donor C57BL/6J mice $(\mathbf{e}, \mathbf{h})$ and recipient Rag $1^{-1-}$ mice $(\mathbf{f}, \mathbf{i})$ and the body weight increment ratios of recipients during HFD feeding $(\mathbf{g}, \mathbf{j})$ were recorded after weight loss $(\mathbf{e}-\mathbf{g})$ and after 1 month of weight maintenance (h-j), respectively. The cell collection time is indicated by a black arrow. Data are shown as means \pm s.d. ${ }^{* *}{ }^{*} P<0.001$, unpaired Student's $t$-test. ${ }^{\S \S \$} P<0.001$, two-way ANOVA followed by the Bonferroni post hoc test. HFD, high fat diet; Ns, no significance.

obesity memory to Rag1 $1^{-/-}$recipient mice was achieved using the $\mathrm{MOH}$ splenocytes (Figures $3 \mathrm{i}$ and $\mathrm{j}$ ). Therefore, we conclude that immune cells are responsible for the obesity memory.

CD4+ $\mathrm{T}$ cells contribute to the obesity memory

To examine whether $\mathrm{T}$ cells contributed to the weight regain, TCR $\beta^{-1-}$ mice, which are deficient in both CD4+ and CD8+ $\mathrm{T}$ cells, ${ }^{35}$ were subjected to the weight gain-loss-regain cycle. We found that $\mathrm{MOH} \mathrm{TCR} \beta^{-/-}$mice were unable to establish obesity memory and gained similar body weights to those of the CTR cohort during the regain period (Supplementary Figures $6 \mathrm{a}$ and $\mathrm{b}$ ). Correspondingly, $\mathrm{MOH} \mathrm{TCR} \beta^{-/-}$mice showed normal glucose metabolism and insulin sensitivity after weight loss (Supplementary Figures 6c-e). These results suggest that $\mathrm{T}$ cells are crucial for establishing obesity memory.

To determine which subset of $\mathrm{T}$ cells is necessary for obesity memory, adipose tissue-resident $\mathrm{T}$ cells were isolated from C57BL/6J mice that had experienced obesity and different categories of T cells were counted. We found that CD4+ effector T lymphocytes, including Th1 and Th17 cells, were noticeably increased in epididymal adipose tissue of $\mathrm{MOH}$ C57BL/6J mice (Supplementary Figure 7), suggesting a vital role of $\mathrm{CD} 4+$ $\mathrm{T}$ cells. Therefore, $\mathrm{H} 2 \mathrm{~A}^{-1-}$ mice, which lack $\mathrm{CD} 4+\mathrm{T}$ cells, were subjected to the weight gain-loss-regain model. DIO $\mathrm{H} 2 \mathrm{~A}^{-/-}$ mice failed to establish obesity memory and displayed similar weight regain rates to those of CTR $\mathrm{H}_{2} \mathrm{~A}^{-/-}$mice (Figures $4 \mathrm{a}$ and $\mathrm{b}$ ). These results suggest that $\mathrm{T}$ cells, and particularly CD4+ $\mathrm{T}$ cells, have an important role in establishing obesity memory. 
a

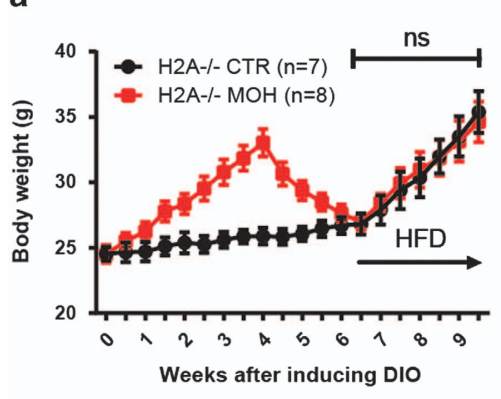

e

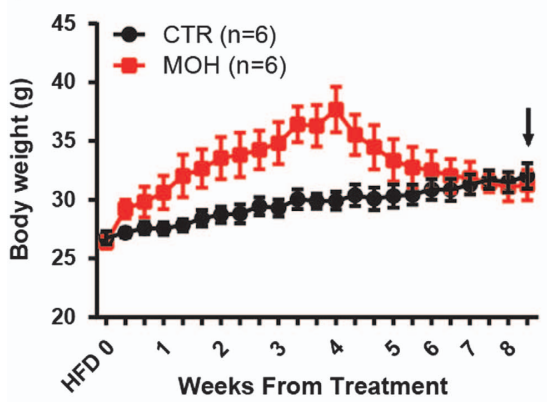

h

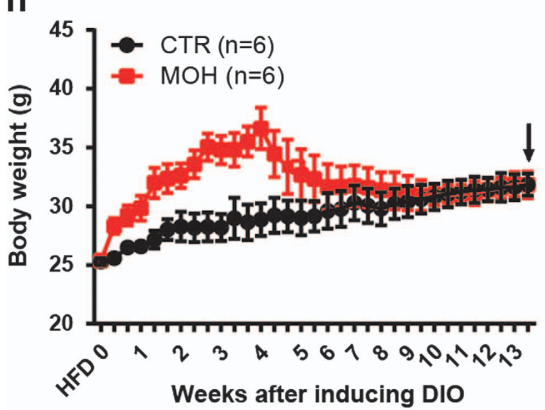

b

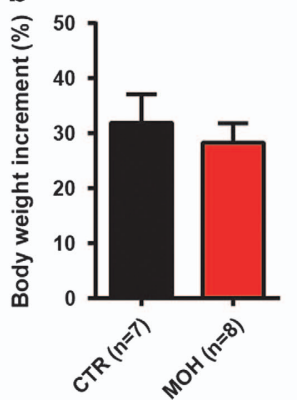

f

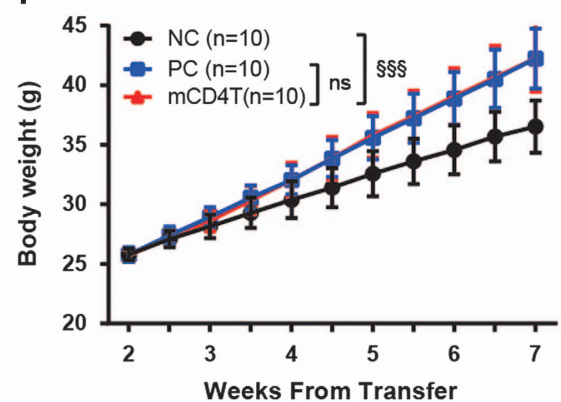

i

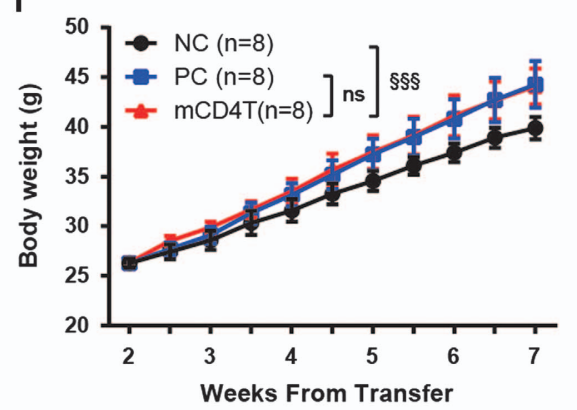

C

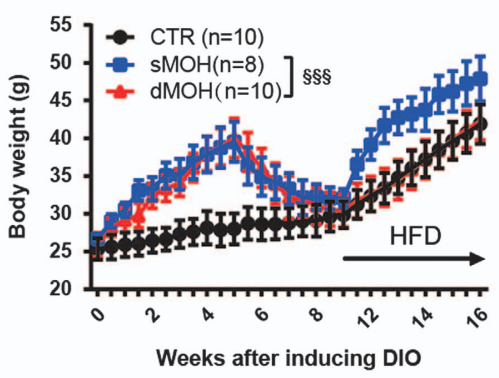

d

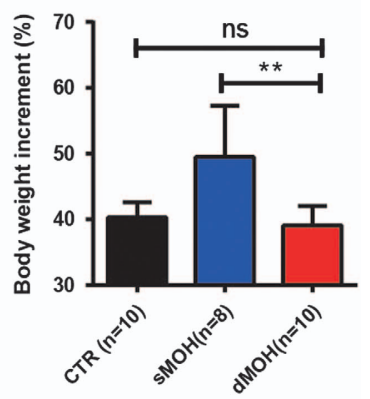

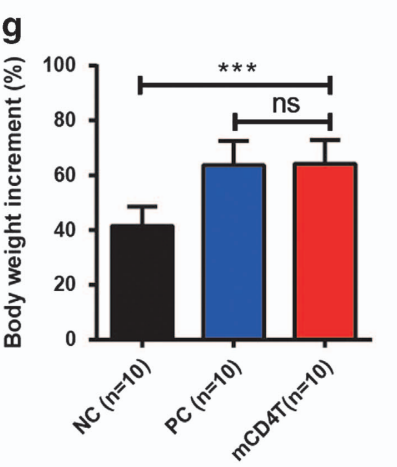

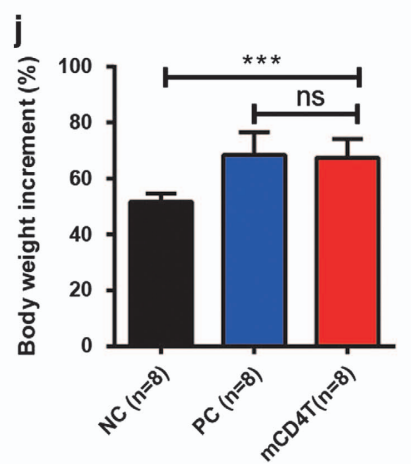

Figure 4 Role of CD4+ T cells in establishing and storing obesity memory. CD4+T cell-deficient $\mathrm{H} 2 \mathrm{~A}^{-1-}$ mice were subjected to the weight gain-loss-regain cycle. Body weight curve (a) and body weight increment ratio values during the weight regain period (b) were recorded to examine obesity memory in $\mathrm{H} 2 \mathrm{~A}^{-1-}$ mice. $\mathrm{MOH}$ C57BL/6J mice were injected with an anti-CD4 antibody (dMOH) or corresponding isotype IgG $(\mathrm{sMOH})$ to determine the role of $\mathrm{CD} 4+\mathrm{T}$ cells in obesity memory. CTR C57BL/6J mice were injected with saline. The injection time is indicated with a black arrow. Body weight curve (c) and body weight increment ratio values during the weight regain period (d) were recorded to examine obesity memory. Adoptive transfer of CD4+ T cells was conducted to confirm their role in memorizing obesity. The body weight curves of donor $\operatorname{C57BL} / 6 \mathrm{~J}(\mathbf{e}, \mathbf{h})$ and recipient Rag $1^{-1-}$ mice $(\mathbf{f}, \mathbf{i})$ and the body weight increment ratios of recipients during the HFD feeding period $(\mathbf{g}, \mathbf{j})$ were recorded after weight loss $(\mathbf{e}-\mathbf{g})$ and after 1 month of weight maintenance (h-j), respectively. The cell collection time is indicated by a black arrow. Data are shown as means \pm s.d. ${ }^{*} P<0.05,{ }^{*} P<0.01$ and ${ }^{* * *} P<0.001$, unpaired Student's $t$-test. ${ }^{\S \S} P<0.001$, two-way ANOVA followed by the Bonferroni post hoc test. CTR, control group; dMOH, CD4+ T cell-deficient MOH group; HFD, high fat diet; mCD4T, CD4+ T cells carrying obesity memory group; $\mathrm{MOH}$, obesity history group; NC, negative control group; Ns, no significance; PC, positive control group; sMOH, CD4+ T cell-sufficient $\mathrm{MOH}$ group.

To further confirm the requirement of CD4+ $\mathrm{T}$ cells in obesity memory, CD4+ T cells were depleted in C57BL/6J mice after weight loss by administration of an anti-CD4 antibody that did not affect CD8+ T cells and B cells (Supplementary Figures $8 \mathrm{a}$ and $\mathrm{b})$. Compared with the CD4+ T cell-sufficient $\mathrm{MOH}(\mathrm{sMOH}$, injected with an isotype IgG2b\% antibody) and CTR mice (injected with saline), the obesity memory in the $\mathrm{CD} 4+\mathrm{T}$ cell-deficient $\mathrm{MOH}$ mice $(\mathrm{dMOH}$, injected with antiCD4 antibody) was completely eliminated (Figures $4 \mathrm{c}$ and d), suggesting that $\mathrm{CD} 4+\mathrm{T}$ cells are indispensable for obesity memory. To further explore the role of $\mathrm{CD} 4+\mathrm{T}$ cells, we collected splenocytes from CTR and $\mathrm{MOH}$ mice after weight loss and isolated CD4+ T cells with magnetic beads (Figure 4e). Then, CD4+ $\mathrm{T}$ cells from $\mathrm{MOH}$ mice and $\mathrm{CD} 4+\mathrm{T}$ cellremoved splenocytes from CTR mice were mixed and transferred into naive $\mathrm{Rag1}^{-/-}$recipient mice $(\mathrm{mCD} 4 \mathrm{~T}, \mathrm{CD} 4+$ $\mathrm{T}$ cells carrying obesity memory). Thus, this splenocyte mixture contained $\mathrm{CD} 4+\mathrm{T}$ cells that might carry obesity memory and 
other splenocytes that did not carry obesity memory. Rag1 ${ }^{-/-}$ mice transferred with total splenocytes of CTR and $\mathrm{MOH}$ mice were used as negative controls (NC) and positive controls (PC), respectively. After 2 weeks of transfer, Rag $1^{-1-}$ recipients were fed with HFD to induce obesity. Interestingly, the body weight increment ratio of the mCD4T cohort was similar to that of the PC mice, and it was significantly greater than that of the NC cohort (Figures $4 \mathrm{f}$ and $\mathrm{g}$ ). In addition, we isolated CD4+ T cells from donors that experienced 1 month of weight maintenance (Figure $4 \mathrm{~h}$ ) and conducted the transfer experiment again. Remarkably, a higher rate of weight gain was observed in mCD4T recipients when compared with the NC counterparts (Figures $4 \mathrm{i}$ and $\mathrm{j}$ ). These results demonstrate that CD4+ T cells are the key contributors to the storage and transfer of obesity memory.

\section{DISCUSSION}

Obesity has become one of the most serious health problems globally, and the obese and overweight populations are growing rapidly ${ }^{36}$ It is difficult to reduce weight, while maintaining a long-term reduced weight is also a huge challenge., ${ }^{9,37}$ Physiological adaptions have been regarded as the potential cause of weight regain. ${ }^{37,38}$ However, we showed that no significant metabolic alterations were observed after weight loss and that they were not the major reason for obesity relapse. Instead, faster weight regains were related to dysregulated immune activation, which is consistent with the observation that enhanced inflammation is induced by weight fluctuation. ${ }^{39-42}$ We observed that circulating and adipose tissue-resident $\mathrm{T}$ cells were present at higher levels in the weight-lost mice when compared with the weight-matched normal mice. Mice with severe immune deficiency failed to develop obesity memory. Furthermore, we found that obesity memory was stored in immune cells and could be adoptively transferred to immunedeficient mice.

It is known that obesity triggers chronic inflammation in white adipose tissue, represented by accumulated effector lymphocytes, including CD4+ T cells. ${ }^{43}$ Fat-produced leptin can induce $\mathrm{CD} 4+\mathrm{T}$ cell proliferation and activation showing increased expression of early and late activation markers. ${ }^{44}$ Here, we show that $\mathrm{CD} 4+\mathrm{T}$ cells are also related to obesity memory. CD4+ effector T cells, including Th1 and Th17 cells, accumulated in adipose tissue before weight regain. CD4+ $\mathrm{T}$ cell-deficient $\mathrm{H}_{2} \mathrm{~A}^{-/-}$mice were unable to establish obesity memory. Depletion of CD4+ T cells prevented obesity memory development, suggesting that obesity memory depends on CD4+ effector T cells. Surprisingly, we also observed that the weight regain was accelerated when we introduced $\mathrm{CD} 4+$ $\mathrm{T}$ cells of previously obese mice into $\mathrm{Ragl}^{-/-}$mice. These results suggest that $\mathrm{CD} 4+\mathrm{T}$ cells have a vital role in establishing obesity memory.

It is difficult to identify the specific antigens that trigger the activation of these obesity memory-related CD4+ T cells. Although it was reported that fatty acids could promote the proliferation of memory-like CD4+ T cells, it is still unknown whether they are able to directly activate $\mathrm{CD} 4+\mathrm{T}$ cells and trigger obesity relapse. ${ }^{45}$ Meanwhile, there are many different subsets of CD4+ T cells that have been associated with obesity and inflammation in adipose tissue. Th1-polarized cells were reported to be associated with inflammation and insulin resistance in obesity. ${ }^{46}$ IFN $\gamma$, a prototypical Th1 cytokine, was increased in obese adipose tissue and promotes obesityrelated inflammation. ${ }^{47}$ Th1 responses could be promoted by M1 macrophage-mediated NKT cell activation, which therefore exacerbated obesity and chronic inflammation. ${ }^{48}$ Th17 cells, another pro-inflammatory $\mathrm{T}$ cell subtype, infiltrated obese adipose tissue, and Th17 cytokines promoted TNF- $\alpha$ production in obese and metabolically unhealthy individuals. ${ }^{49,50}$ Although our data show that Th1 and Th17 were increased after weight loss, their functions in obesity memory remain unknown. On the other hand, Tregs, known as an important immune-suppressive CD4+ T cell subset, are abundant in the adipose tissue of normal mice but are reduced in proportion in obese mice. ${ }^{51}$ Depletion of Tregs leads to adipose tissue inflammation and metabolic abnormalities. ${ }^{52,53}$ In particular, visceral adipose tissue-resident Tregs have been reported as a crucial suppressor of obesity-associated inflammation. ${ }^{25,26}$ Further studies are required to identify the role of Tregs in obesity memory.

Previous studies suggest that many cytokines are associated with obesity-related inflammation and weight regain. Proinflammatory cytokines and chemokines, including IFN $\gamma$, IL-6 and IL-1 $\beta$, can be induced by leptin. ${ }^{44}$ Monocyte chemoattractant protein-1 (MCP-1), which was increased in HFD-induced obesity, remained at higher levels after weight loss and during weight regain. ${ }^{41}$ High TNF- $\alpha$ levels in white adipose tissue were detected in weight-loss patients. ${ }^{30}$ Weight regain could be predicted by higher CRP and IL- $1 \beta$ levels, whereas successful weight maintenance was associated with lower levels of these proteins. ${ }^{31}$ IL-25, a member of the IL-17 family, reduced body weight gain and alleviated lipid accumulation in adipose tissue via stimulating M2 macrophage polarization. ${ }^{54}$ Here, we also observed elevated IFN $\gamma$ expression in adipose tissue before and after weight regain. The abovementioned inflammatory cytokines and their functions in obesity memory require further study.

Physical activity seems to be the most beneficial approach for promoting long-term weight loss and preventing weight regain. ${ }^{55}$ It was recently reported that strengthening physical activity promotes immune system hypofunction. ${ }^{56}$ Although upregulation of inflammatory molecules, including hsCRP, IL-1, TNF- $\alpha$ and TNF receptor, could be reversed through dieting, physical exercise was shown to be essential to keep these inflammatory molecules at low levels. ${ }^{56,57}$ Our data show that immune cell-induced inflammatory status facilitates obesity relapse, which may also implicate the efficacy of dietingplus-exercise treatment.

In conclusion, we provide new insight into the mechanism of weight regain. Obesity can be memorized by immune cells and stored in $\mathrm{CD} 4+\mathrm{T}$ cells, resulting in unavoidable weight regain. With further investigation into the specific antigens and 
CD4+ T lymphocyte subtypes involved in obesity memory, we may develop more efficient anti-obesity strategies.

\section{CONFLICT OF INTEREST}

The authors declare no conflict of interest.

\section{ACKNOWLEDGEMENTS}

We thank Dr Jiong Chen for manuscript editing assistance; Dr Dejing Pan for technical suggestions; Dr Yun Wang for immunosuppression experiment advice; and Dr Jianghuai Liu, Dr Demin Wang, Dr Quan Zhao and Dr Ying Xu for their experimental design suggestions and advice. This work was supported by the National Natural Science Foundation of China (Grant 31301217) and the Ministry of Science and Technology of China (Grants 2015BAI08B02 and 2014BAI02B01).

1 Yoon KH, Lee JH, Kim JW, Cho JH, Choi YH, Ko SH et al. Epidemic obesity and type 2 diabetes in Asia. Lancet 2006; 368: 1681-1688.

2 Apovian CM. Obesity: definition, comorbidities, causes, and burden. Am J Manag Care 2016; 22: s176-s185.

3 Kahn SE, Hull RL, Utzschneider KM. Mechanisms linking obesity to insulin resistance and type 2 diabetes. Nature 2006; 444: 840-846.

4 Woo Baidal JA, Lavine JE. The intersection of nonalcoholic fatty liver disease and obesity. Sci Trans/ Med 2016; 8: 323rv321.

5 Kraschnewski JL, Boan J, Esposito J, Sherwood NE, Lehman EB, Kephart DK et al. Long-term weight loss maintenance in the United States. Int J Obes 2010; 34: 1644-1654.

6 Svetkey LP, Stevens VJ, Brantley PJ, Appel LJ, Hollis JF, Loria CM et al. Comparison of strategies for sustaining weight loss: the weight loss maintenance randomized controlled trial. JAMA 2008; 299: 1139-1148.

7 Wadden TA, Neiberg RH, Wing RR, Clark JM, Delahanty LM, Hill JO et al. Four-year weight losses in the Look AHEAD study: factors associated with long-term success. Obesity 2011; 19: 1987-1998.

8 Look ARG. Eight-year weight losses with an intensive lifestyle intervention: the look AHEAD study. Obesity 2014; 22: 5-13.

9 Langeveld M, DeVries JH. The long-term effect of energy restricted diets for treating obesity. Obesity 2015; 23: 1529-1538.

10 Gursoy A, Erdogan MF, Cin MO, Cesur M, Baskal N. Comparison of orlistat and sibutramine in an obesity management program: efficacy, compliance, and weight regain after noncompliance. Eat Weight Disord 2006; 11: e127-e132.

11 Odom J, Zalesin KC, Washington TL, Miller WW, Hakmeh B, Zaremba $\mathrm{DL}$ et al. Behavioral predictors of weight regain after bariatric surgery. Obes Surg 2010; 20: 349-356.

12 Smith SR, Weissman NJ, Anderson CM, Sanchez M, Chuang E, Stubbe $\mathrm{S}$ et al. Multicenter, placebo-controlled trial of lorcaserin for weight management. N Engl J Med 2010; 363: 245-256.

13 Sjostrom L, Lindroos AK, Peltonen M, Torgerson J, Bouchard C, Carlsson $\mathrm{B}$ et al. Lifestyle, diabetes, and cardiovascular risk factors 10 years after bariatric surgery. N Engl J Med 2004; 351: 2683-2693.

14 Dietz WH, Goodwin NJ, Hill JO, Pi-Sunyer FX, Rolls B, Stern J et al. Long-term pharmacotherapy in the management of obesity. National Task Force on the prevention and treatment of obesity. JAMA 1996; 276: 1907-1915.

15 Kliewer KL, Ke JY, Lee HY, Stout MB, Cole RM, Samuel VT et al. Short-term food restriction followed by controlled refeeding promotes gorging behavior, enhances fat deposition, and diminishes insulin sensitivity in mice. J Nutr Biochem 2015; 26: 721-728.

16 Cummings DE, Weigle DS, Frayo RS, Breen PA, Ma MK, Dellinger EP et al. Plasma ghrelin levels after diet-induced weight loss or gastric bypass surgery. N Engl J Med 2002; 346: 1623-1630.

17 le Roux CW, Welbourn R, Werling M, Osborne A, Kokkinos A, Laurenius A et al. Gut hormones as mediators of appetite and weight loss after Roux-en-Y gastric bypass. Ann Surg 2007; 246: 780-785.
18 de Luis DA, Gonzalez Sagrado M, Conde R, Aller R, Izaola O. Decreased basal levels of glucagon-like peptide- 1 after weight loss in obese subjects. Ann Nutr Metab 2007; 51: 134-138.

19 Sumithran P, Prendergast LA, Delbridge E, Purcell K, Shulkes A, Kriketos $A$ et al. Long-term persistence of hormonal adaptations to weight loss. N Engl J Med 2011; 365: 1597-1604.

20 Ebbeling CB, Swain JF, Feldman HA, Wong WW, Hachey DL, Garcia-Lago $\mathrm{E}$ et al. Effects of dietary composition on energy expenditure during weight-loss maintenance. JAMA 2012; 307: 2627-2634.

21 Crujeiras AB, Goyenechea E, Abete I, Lage M, Carreira MC, Martinez JA et al. Weight regain after a diet-induced loss is predicted by higher baseline leptin and lower ghrelin plasma levels. J Clin Endocrinol Metab 2010; 95: 5037-5044.

22 Chaput JP, Pelletier C, Despres JP, Lemieux S, Tremblay A. Metabolic and behavioral vulnerability related to weight regain in reduced-obese men might be prevented by an adequate diet-exercise intervention. Appetite 2007; 49: 691-695.

23 McLaughlin T, Liu LF, Lamendola C, Shen L, Morton J, Rivas H et al. T-cell profile in adipose tissue is associated with insulin resistance and systemic inflammation in humans. Arterioscler Thromb Vasc Biol 2014; 34: 2637-2643.

24 Kintscher U, Hartge M, Hess K, Foryst-Ludwig A, Clemenz M, Wabitsch $\mathrm{M}$ et al. T-lymphocyte infiltration in visceral adipose tissue: a primary event in adipose tissue inflammation and the development of obesity-mediated insulin resistance. Arterioscler Thromb Vasc Biol 2008; 28: 1304-1310.

25 Vasanthakumar A, Moro K, Xin A, Liao Y, Gloury R, Kawamoto S et al. The transcriptional regulators IRF4, BATF and IL-33 orchestrate development and maintenance of adipose tissue-resident regulatory T cells. Nat Immunol 2015; 16: 276-285.

$26 \mathrm{Hu} \mathrm{ZQ}$, Zhao WH. The IL-33/ST2 axis is specifically required for development of adipose tissue-resident regulatory $\mathrm{T}$ cells. Cell $\mathrm{Mol}$ Immunol 2015; 12: 521-524.

27 Kong LC, Wuillemin PH, Bastard JP, Sokolovska N, Gougis S, Fellahi S et al. Insulin resistance and inflammation predict kinetic body weight changes in response to dietary weight loss and maintenance in overweight and obese subjects by using a Bayesian network approach. Am J Clin Nutr 2013; 98: 1385-1394.

28 Anderson EK, Gutierrez DA, Kennedy A, Hasty AH. Weight cycling increases T-cell accumulation in adipose tissue and impairs systemic glucose tolerance. Diabetes 2013; 62: 3180-3188.

29 Winer S, Chan Y, Paltser G, Truong D, Tsui H, Bahrami J et al. Normalization of obesity-associated insulin resistance through immunotherapy. Nat Med 2009; 15: 921-929.

30 Schmitz J, Evers N, Awazawa M, Nicholls HT, Bronneke HS, Dietrich A et al. Obesogenic memory can confer long-term increases in adipose tissue but not liver inflammation and insulin resistance after weight loss. Mol Metab 2016; 5: 328-339.

31 Ambeba EJ, Styn MA, Kuller LH, Brooks MM, Evans RW, Burke LE. Longitudinal effects of weight loss and regain on cytokine concentration of obese adults. Metabolism 2013; 62: 1218-1222.

32 Maclean PS, Bergouignan A, Cornier MA, Jackman MR. Biology's response to dieting: the impetus for weight regain. Am J Physiol Regul Integr Comp Physiol 2011; 301: R581-R600.

33 Mombaerts P, lacomini J, Johnson RS, Herrup K, Tonegawa S, Papaioannou VE. RAG-1-deficient mice have no mature $B$ and T lymphocytes. Cell 1992; 68: 869-877.

34 Diehl R, Ferrara F, Muller C, Dreyer AY, McLeod DD, Fricke S et al. Immunosuppression for in vivo research: state-of-the-art protocols and experimental approaches. Cell Mol Immunol 2017; 14: 146-179.

35 Mombaerts P, Clarke AR, Rudnicki MA, lacomini J, Itohara S, Lafaille $\mathrm{JJ}$ et al. Mutations in T-cell antigen receptor genes alpha and beta block thymocyte development at different stages. Nature 1992; 360: 225-231.

36 Popkin BM, Gordon-Larsen P. The nutrition transition: worldwide obesity dynamics and their determinants. Int J Obes Relat Metab Disord 2004; 28(Suppl 3): S2-S9.

37 Leibel RL, Rosenbaum M, Hirsch J. Changes in energy expenditure resulting from altered body weight. $N$ Engl J Med 1995; 332: 621-628.

38 Greenway FL. Physiological adaptations to weight loss and factors favouring weight regain. Int J Obes 2015; 39: 1188-1196. 
39 Blomain ES, Dirhan DA, Valentino MA, Kim GW, Waldman SA. Mechanisms of weight regain following weight loss. ISRN Obes 2013; 2013: 210524

40 Thaiss CA, Itav S, Rothschild D, Meijer M, Levy M, Moresi C et al. Persistent microbiome alterations modulate the rate of post-dieting weight regain. Nature 2016; 540: 544-551.

41 Barbosa-da-Silva S, Fraulob-Aquino JC, Lopes JR, Mandarim-deLacerda CA, Aguila MB. Weight cycling enhances adipose tissue inflammatory responses in male mice. PLoS ONE 2012; 7: e39837.

42 Strohacker K, McFarlin BK. Influence of obesity, physical inactivity, and weight cycling on chronic inflammation. Front Biosci (Elite Ed) 2010; 2: 98-104.

43 Mathis D. Immunological goings-on in visceral adipose tissue. Cell Metab 2013; 17: 851-859.

44 Vadacca M, Margiotta DP, Navarini L, Afeltra A. Leptin in immunorheumatological diseases. Cell Mol Immunol 2011; 8: 203-212.

45 Mauro C, Smith J, Cucchi D, Coe D, Fu H, Bonacina F et al. Obesityinduced metabolic stress leads to biased effector memory CD4+ T cell differentiation via PI3K p110delta-Akt-mediated signals. Cell Metab 2017; 25: 593-609.

46 Strissel KJ, DeFuria J, Shaul ME, Bennett G, Greenberg AS, Obin MS. T-cell recruitment and Th1 polarization in adipose tissue during dietinduced obesity in C57BL/6 mice. Obesity 2010; 18: 1918-1925.

47 Rocha VZ, Folco EJ, Sukhova G, Shimizu K, Gotsman I, Vernon AH et al. Interferon-gamma, a Th1 cytokine, regulates fat inflammation: a role for adaptive immunity in obesity. Circ Res 2008; 103: 467-476.

48 Zhang H, Xue R, Zhu S, Fu S, Chen Z, Zhou R et al. M2-specific reduction of CD1d switches NKT cell-mediated immune responses and triggers metaflammation in adipose tissue. Cell Mol Immunol 2017; 14: $1-12$.

49 Pandolfi JB, Ferraro AA, Sananez I, Gancedo MC, Baz P, Billordo LA et al. ATP-induced inflammation drives tissue-resident Th17 cells in metabolically unhealthy obesity. J Immunol 2016; 196: 3287-3296.

50 Ip B, Cilfone NA, Belkina AC, DeFuria J, Jagannathan-Bogdan M, Zhu $M$ et al. Th17 cytokines differentiate obesity from obesity-associated type 2 diabetes and promote TNFalpha production. Obesity 2016; 24: $102-112$.

51 Zhou X, Tang J, Cao H, Fan H, Li B. Tissue resident regulatory T cells: novel therapeutic targets for human disease. Cell Mol Immunol 2015; 12: 543-552.
52 Chen X, Wu Y, Wang L. Fat-resident Tregs: an emerging guard protecting from obesity-associated metabolic disorders. Obes Rev 2013; 14: 568-578.

53 Eller K, Kirsch A, Wolf AM, Sopper S, Tagwerker A, Stanzl U et al. Potential role of regulatory $T$ cells in reversing obesity-linked insulin resistance and diabetic nephropathy. Diabetes 2011; 60: 2954-2962.

54 Feng J, Li L, Ou Z, Li Q, Gong B, Zhao Z et al. IL-25 stimulates M2 macrophage polarization and thereby promotes mitochondrial respiratory capacity and lipolysis in adipose tissues against obesity. Cell Mol Immunol 2017.

55 Donnelly JE, Blair SN, Jakicic JM, Manore MM, Rankin JW, Smith BK et al. Appropriate physical activity intervention strategies for weight loss and prevention of weight regain for adults. Med Sci Sports Exerc 2009; 41: 459-471.

56 Snel M, van Diepen JA, Stijnen T, Pijl H, Romijn JA, Meinders AE et al. Immediate and long-term effects of addition of exercise to a 16-week very low calorie diet on low-grade inflammation in obese, insulindependent type 2 diabetic patients. Food Chem Toxicol 2011; 49: 3104-3111.

57 You T, Berman DM, Ryan AS, Nicklas BJ. Effects of hypocaloric diet and exercise training on inflammation and adipocyte lipolysis in obese postmenopausal women. J Clin Endocrinol Metab 2004; 89: $1739-1746$

(c) (i) (-) $\odot$ This work is licensed under a Creative Commons Attribution-NonCommercial-NoDerivs 4.0 International License. The images or other third party material in this article are included in the article's Creative Commons license, unless indicated otherwise in the credit line; if the material is not included under the Creative Commons license, users will need to obtain permission from the license holder to reproduce the material. To view a copy of this license, visit http://creativecommons.org/licenses/by-nc-nd/4.0/

(C) The Author(s) 2017

Supplementary Information for this article can be found on the Cellular \& Molecular Immunology website (http://www.nature.com/cmi) 